\title{
Comparative evaluations of lignocellulose reactivity and usability in transgenic rice plants with altered lignin composition
}

\author{
Yuri Takeda ${ }^{1} \mathbb{D}$, Yuki Tobimatsu ${ }^{1 *} \mathbb{D}$, Masaomi Yamamura ${ }^{1}$, Toshiyuki Takano² ${ }^{\mathbb{D}}$, Masahiro Sakamoto² \\ and Toshiaki Umezawa ${ }^{1,3^{*}}$ (i)
}

\begin{abstract}
The aromatic composition of lignins is considered an important trait that affects the physico-chemical properties of lignocellulosic biomass. However, our knowledge of the relationship between lignin structure and biomass utilization properties remains limited, especially in monocotyledonous grass species, despite their potential as biomass feedstocks. In this study, we used recently produced rice transgenic lines with distinct lignin monomer compositions, i.e., guaiacyl (G)/syringyl (S)/p-hydroxyphenyl (H) aromatic unit ratios, to study the impact of lignin composition on the chemical reactivity, enzymatic saccharification efficiency and calorific value of rice lignocellulose. The H-ligninenriched rice transgenic line showed significantly enhanced biomass saccharification efficiency after alkali and acid pretreatments and even without any pretreatment, whereas the S-lignin-enriched rice transgenic line displayed enhanced saccharification efficiency after liquid hot water pretreatment. While we detected no significant differences in biomass heating values between the transgenic rice materials tested, analysis of synthetic lignins comprising only $\mathrm{G}, \mathrm{S}$ or $\mathrm{H}$ units suggested that increased ratios of $\mathrm{G}$ or $\mathrm{H}$ units could increase the heating value of lignin-based solid biofuels.
\end{abstract}

Keywords: p-Coumaroyl ester 3-hydroxylase, Coniferaldehyde 5-hydroxylase, Enzymatic saccharification, Heating value, Grass biomass

\section{Introduction}

The production and utilization of sustainable resources and energy are becoming increasingly important to follow a sustainable development path by achieving socalled SDGs (sustainable development goals) [1]. Biomass is a particularly important sustainable feedstock, because it can provide not only energy but also organic substances, including liquid fuels, that are not available from most other sustainable energy sources currently under consideration (e.g., solar, hydraulic and wind power). In particular, lignocellulosic biomass, a plant-derived biocomposite composed of cellulose, hemicelluloses and

\footnotetext{
*Correspondence: ytobimatsu@rish.kyoto-u.ac.jp;

tumezawa@rish.kyoto-u.ac.jp

${ }^{1}$ Research Institute for Sustainable Humanosphere, Kyoto University, Uji,

Kyoto 611-0011, Japan

Full list of author information is available at the end of the article
}

lignins, accounts for the highest proportion of global terrestrial biomass; the estimated annual production of lignocellulosic biomass is approximately $5600 \mathrm{M}$ tons, of which approximately $2000 \mathrm{M}$ tons are derived from trees and the rest (approximately $3600 \mathrm{M}$ tons) from non-tree species, mostly grasses $[2,3]$.

While tree biomass is necessary for the production of wood materials and pulp and paper commodities, grasses are a prominent plant group that show great potential as biomass feedstocks. Huge amounts of lignocellulose are produced annually as agricultural residues from grass grain crops, such as maize, wheat, rice, barley, Sorghum and millet. In addition, large-sized perennial grass species, such as Erianthus, Miscanthus, switchgrass and bamboo, have attracted considerable attention as potent biomass sources because of their higher lignocellulose productivity and better biomass processability than 
typical tree species [2-4]. Furthermore, grass biomass may provide more output than tree biomass. For example, major grass crops, such as sugarcane, maize and Sorghum, produce grains that can be used for food, cattle feed and/or fermentation feedstocks, while the residual straw, which is mainly composed of lignocellulose, can be utilized for combustion fuels, fiber materials and/or other various polysaccharide- and lignin-derived biofuels and biochemicals. In fact, sugarcane-based sugar factories use sugarcane bagasse residue as a combustion fuel that can easily cover all the energy demands within the factories $[5,6]$.

Lignins, which are complex phenylpropanoid polymers typically accounting for $15-30 \%$ of lignocellulosic biomass, display considerable structural heterogeneity. In general, lignins in gymnosperms (softwoods) are composed mainly of guaiacyl (G) aromatic units derived via polymerization of coniferyl alcohol, whereas lignins in angiosperms, i.e., in both eudicots (e.g., hardwoods) and monocots including grasses, incorporate $G$ and syringyl (S) aromatic units from sinapyl alcohol; both gymnosperm and angiosperm lignins also contain a small amount of $p$-hydroxyphenyl $(\mathrm{H})$ units from $p$-coumaryl alcohol [7]. Unlike eudicot lignins, grass lignins also contain $\gamma$ - $p$-coumaroylated $\mathrm{G}$ and $\mathrm{S}$ units incorporated via polymerization of $\gamma$ - $p$-coumaroylated coniferyl and sinapyl alcohol conjugates [8], as well as flavone tricin units derived via co-polymerization of tricin with monolignols [9]. In addition, abundant ferulates cross-link lignins and hemicelluloses (arabinoxylans) in grass cell walls [8], further making grass cell walls unique and more complicated than gymnosperm and eudicot cell walls.

Traditionally, lignin has been considered the major recalcitrant factor in biomass utilization, particularly because it impedes the utilization of cell wall polysaccharides. Accordingly, metabolic engineering approaches to reduce lignin content and/or to alter lignin structures to mitigate such lignin recalcitrance in polysaccharide utilization have been extensively pursued [3, 4, 10-13]. More recently, bioengineering approaches to manipulate lignin deposition and structures to enhance the recovery and conversion of lignins into useful aromatic chemicals are becoming an important research subject in the light of the biorefinery concept $[3,14,15]$. In addition, as lignin content positively affects the energetic yields of lignocellulose, the manipulation of lignin biosynthetic enzymes or transcriptional factors to enrich lignins against polysaccharides is a potent strategy to improve biomass heating values for better solid fuel applications $[3,16,17]$.

Currently, however, the relationships between lignin chemical structures and various lignocellulose utilization properties are not fully understood, mainly due to the intricate lignin structures that show great variability among different biomass sources. In this respect, transgenic plants containing engineered lignins represent a powerful model system to investigate the effects of altered lignin structures on various lignocellulose properties. Indeed, eudicot model plants, such as Arabidopsis, poplar and alfalfa, have been used to study these effects in eudicot biomass [18-23]. However, few efforts have been made to systematically investigate the effects of lignin structures on lignocellulose utilization properties in grasses despite their importance as biomass feedstocks, possibly due to the limited transgenic materials with altered lignin structures available in grasses. In fact, as aforementioned, the structural organization of lignins in grasses substantially differs from those in eudicots and gymnosperm species, and therefore studies using appropriate grass model plants, such as rice, maize and Brachypodium, are essential to characterize the unique biosynthesis, structures and properties of grass lignins [3, 4, 24-26].

We recently succeeded in generating transgenic rice lines that produce lignins with distinct aromatic compositions: down- and up-regulation of a gene encoding coniferaldehyde 5-hydroxylase (OsCAld5H1), an enzyme catalyzing the key reaction step in the lignin biosynthetic pathway for S-lignin units, produced altered lignins enriched in $\mathrm{G}$ and $\mathrm{S}$ units, respectively $[27,28]$, while the down-regulation of a gene encoding $p$-coumaroyl ester 3-hydroxylase $\left(\mathrm{OsC} 3^{\prime} \mathrm{H} 1\right)$, an entry enzyme in the main lignin biosynthetic pathway leading to the formation of $\mathrm{G}$ and $\mathrm{S}$ units but not $\mathrm{H}$ units, produced lignins largely enriched in $\mathrm{H}$ units [29]. Given that the H-/G-/S-lignin composition is considered an important trait that greatly affects the physico-chemical properties of lignin as well as the usability of lignocellulosic biomass as a whole [3], these transgenic rice lines represent a useful system to study the relationship between the engineered lignin composition and lignocellulose properties in grasses. In this study, we comparatively characterized cell wall materials prepared from these lignin-modified transgenic rice lines in terms of their structures, chemical reactivities in typical biomass processing reactions, i.e., dilute alkali, dilute acid and liquid hot water treatments, enzymatic saccharification with or without chemical pretreatments for fermentable sugar production and calorific values for combustion fuel applications.

\section{Methods/experimental Materials}

The preparation of the OsCAld5H1-knockdown (OsCAld5H1-KD), OsCAld5H1-overexpression (OsCAld5H1-OX), and OsC3'H1-knockdown (OsC3'H1-KD) rice plants (Oryza sativa L. cv. Nipponbare background) has been described previously [27, 
29]. The $T_{3}$ progenies of the rice transgenic lines and wild-type control lines were grown side by side under greenhouse conditions [27]. Mature aerial parts were harvested and dried at $27{ }^{\circ} \mathrm{C}$ for 30 days, and dried culm straws were then collected by removing the panicle, leaf blade and leaf sheath. Culm samples from three plants for each genotype were pooled and homogeneously pulverized with a TissueLyser (Qiagen, Hilden, Germany), and then extracted with methanol, hexane and distilled water to produce extractive free cell wall residues (CWRs) [30]. To prepare lignin-enriched cell wall samples, the CWRs were further ball-milled and digested with crude cellulases according to a previously described method [31]. Dehydrogenation polymers (DHPs) were prepared via peroxidase-catalyzed polymerization of $p$-coumaryl, coniferyl and sinapyl alcohols for H-DHP, G-DHP and S-DHP, respectively, as described previously $[32,33]$.

\section{Alkali, acid and liquid hot water treatments}

Dilute alkali and dilute acid treatments were carried out by heating CWRs in a polypropylene tube containing $31.25 \mathrm{mM}(0.125 \%) \mathrm{NaOH}$ [34] or $1.3 \%(150 \mathrm{mM})$ $\mathrm{H}_{2} \mathrm{SO}_{4}$ solution at $90{ }^{\circ} \mathrm{C}$ for $3 \mathrm{~h}$ [18]. The reaction mixtures were then neutralized with $1 \mathrm{~N} \mathrm{HCl}$ or $6 \mathrm{~N} \mathrm{NaOH}$ solution and the precipitates were collected by centrifugation, washed with distilled water, and then freezedried for cell wall analyses. Liquid hot water treatment was carried out by autoclaving CWRs in a Teflon tube containing distilled water at $200{ }^{\circ} \mathrm{C}$ (35 min heat-up time followed by 10 min hold) using a Metal Reactor TEM-D1000 M (Taiatsu Techno Co., Ltd., Saitama, Japan) [19]. After the reaction, the precipitates were collected by centrifugation, washed with distilled water, and then freeze-dried for cell wall analyses. Mass recovery rate was calculated as follows:

$$
\text { Mass recovery rate }(\%)=C W R_{P} / C W R_{U} \times 100 \text {, }
$$

where $C W R_{U}$ and $C W R_{P}$ are dry weights $(\mathrm{mg})$ of CWRs before and after each treatment, respectively.

\section{Cell wall analyses}

Microscale thioacidolysis, Klason lignin assay, determination of cellulosic (crystalline) and hemicellulosic (amorphous) glycan contents, and ash analysis of CWRs were performed as previously described [29]. Total lignin content was expressed as the sum of the Klason acidinsoluble (corrected by ash content) and acid-soluble lignin contents. NMR analysis of lignin-enriched CWRs was performed on a Bruker Biospin Avance III 800US system (Bruker Biospin, Billerica, MA, USA) equipped with a cryogenically cooled $5 \mathrm{~mm}$ TCI gradient probe using dimethylsulfoxide (DMSO)- $d_{6} /$ pyridine $-d_{5}$ (4:1, $\mathrm{v} / \mathrm{v})$ as a solvent. Adiabatic heteronuclear single-quantum coherence (HSQC) NMR experiments were carried out using standard implementation ("hsqcetgpsp.3") [31, 35]. Data processing and analysis were performed with the Bruker TopSpin 3.5 software (Bruker Biospin, Billerica, MA, USA) and the central DMSO solvent peaks $\left(\delta_{\mathrm{C}} / \delta_{\mathrm{H}}\right.$ : $39.5 / 2.49 \mathrm{ppm}$ ) were used as an internal reference. HSQC plots were obtained with typical matched Gaussian apodization in F2 and squared cosine-bell apodization and one level of linear prediction (16 coefficients) in F1. For volume integration, linear prediction was turned off and no correction factors were used. The normalized HSQC NMR contour intensities shown in Fig. 1 are expressed on a G $+1 / 2 \mathrm{~S}+1 / 2 \mathrm{H}=100 \%$ and $\mathrm{I}+\mathrm{I}^{\prime}+\mathrm{II}+\mathrm{II}^{\prime}+1 / 2 \mathrm{III}+{ }^{1 / 2}$ $\mathrm{III}^{\prime}=100 \%$ basis.

\section{Enzymatic saccharification assays}

Unpretreated CWRs ( $15 \mathrm{mg}$ ) were transferred to polypropylene tubes, destarched and subjected to enzymatic hydrolysis with an enzyme cocktail composed of Celluclast 1.5 L (Novozymes, Bagsvaerd, Denmark) (1.1 FPU), Novozyme 188 (Novozymes) (2.5 CbU) and Ultraflo L (Novozymes) $(65 \mu \mathrm{g})$ in a sodium citrate buffer $(\mathrm{pH} 4.8)$ [36]. The reaction was carried out in a rotary reactor (Heatblock Rotator SN-48BN, Nissin, Saitama, Japan) at $12.5 \mathrm{rpm}$ at $50{ }^{\circ} \mathrm{C}$ for $24 \mathrm{~h}$. The glucose concentration was determined with a Glucose CII test kit (Wako Pure Chemicals Industries, Osaka, Japan) according to the manufacturer's instructions. Cell wall pretreatments and the subsequent enzymatic saccharification assay were performed as follows. Dried CWRs ( $15 \mathrm{mg})$ were added to $1 \mathrm{~mL}$ of $31.25 \mathrm{mM} \mathrm{NaOH}$ or $500 \mu \mathrm{L}$ of $1.3 \%$ $\mathrm{H}_{2} \mathrm{SO}_{4}$ for dilute alkali and acid pretreatments, respectively, and incubated at $90^{\circ} \mathrm{C}$ for $3 \mathrm{~h}[18,34]$. The reaction mixtures were adjusted to $\mathrm{pH} 4-5$ by adding $35 \mu \mathrm{L}$ of $1 \mathrm{~N} \mathrm{HCl}$ or $500 \mu \mathrm{L}$ of $0.52 \mathrm{~N} \mathrm{NaOH}$ for dilute alkali and acid pretreatments, respectively, and then subjected to enzymatic saccharification as described above. For liquid hot water pretreatment, dried CWRs $(\sim 15 \mathrm{mg})$ were autoclaved with $500 \mu \mathrm{L}$ of distilled water at $200{ }^{\circ} \mathrm{C}$ (35 min heat-up time followed by 10 min hold) using a Metal Reactor TEM-D1000 M (Taiatsu Techno Co., Ltd., Saitama, Japan) [19]. After the reaction, the reaction mixtures were diluted with $500 \mu \mathrm{L}$ of distilled water and then subjected to enzymatic saccharification as described above.

\section{Determination of heating values}

The higher heating value (HHV) was calculated based on the elemental composition or measured by bomb calorimetry. The elemental composition ratios of CWR, lignin-enriched CWR and DHP samples were measured using a CHN analyzer (JM-10; J-SCIENCE LAB 


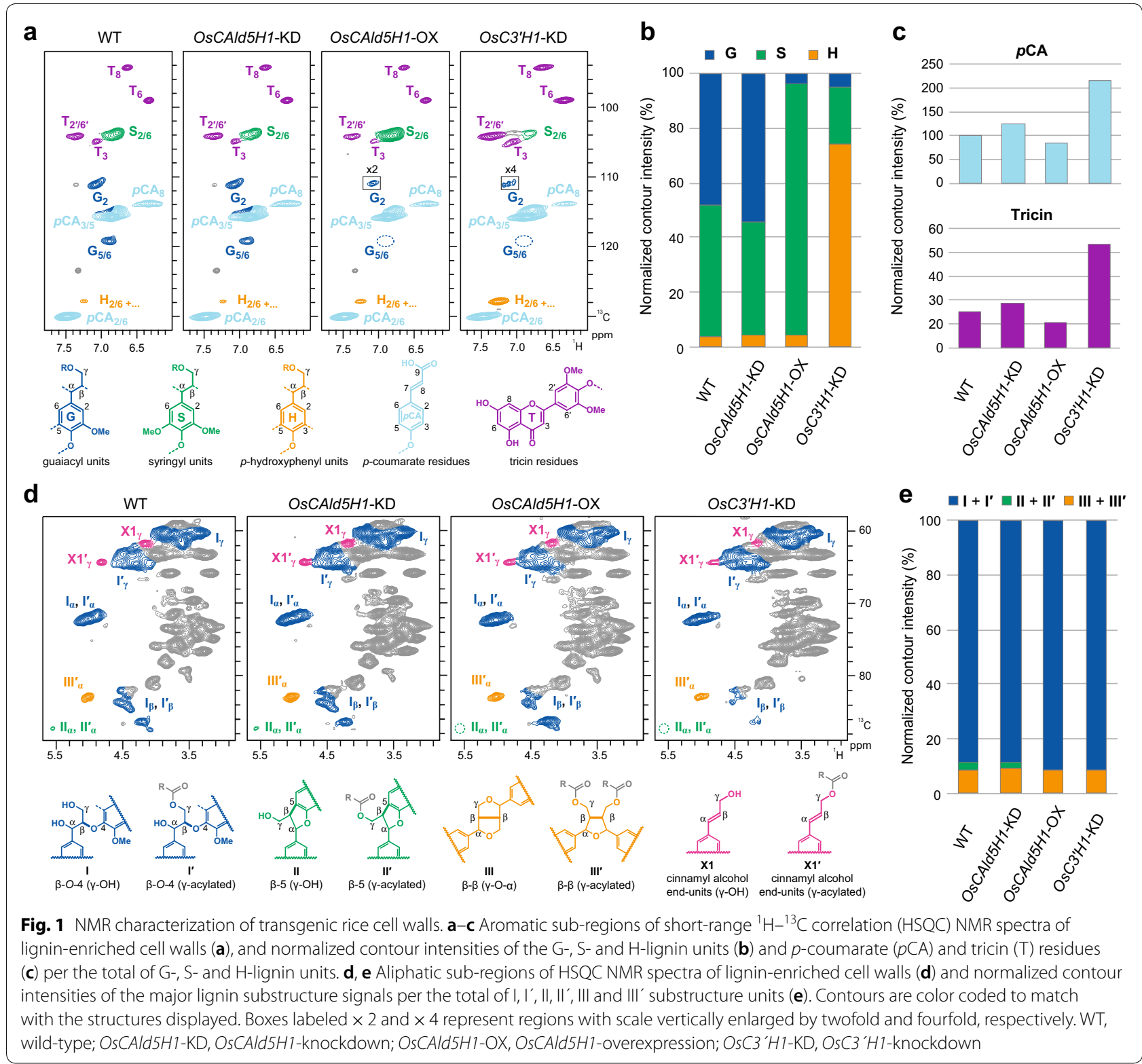

Co., Ltd., Kyoto, Japan). The HHV was calculated based on the equation $\mathrm{HHV}=(0.2949 \mathrm{C}+0.8250 \mathrm{H}) \times 1000$ $(\mathrm{J} / \mathrm{g})$, where $\mathrm{C}$ and $\mathrm{H}$ are mass percentages of carbon and hydrogen, respectively [37]. For bomb calorimetry, each CWR and lignin-enriched CWR sample ( 200 mg) was oven-dried, encapsulated in a gelatin capsule with a known calorific value (IKA-Werke GmbH\&Co, Staufen, Germany), and then subjected to combustion in a bomb calorimeter (IKA C5003 Calorimeter System; IKA-Werke GmbH\&Co, Staufen, Germany). The calorimeter was calibrated by the combustion of a known calorific value fuel (benzoic acid).

\section{Results and discussion}

\section{Cell wall structures in rice transgenic lines}

The previously generated OsCAld5H1-KD, OsCAld5H1-OX and $\mathrm{OsC}^{\prime} \mathrm{H} 1-\mathrm{KD}$ transgenic rice lines $[27,29]$ were grown together with the wild-type control and the cell wall composition of their mature culm cell walls was analyzed. The lignin content estimated by Klason assay [38] was in the range of $15 \%$ to $22 \%$ among the tested genotypes; the highest was in OsCAld5H1KD plants, followed by $O s C 3{ }^{\prime} H 1-\mathrm{KD}$, OsCAld5H1-OX and wild-type control plants (Table 1). The analysis of cellulosic and hemicellulosic glycans by a trifluoroacetic acid (TFA) $/ \mathrm{H}_{2} \mathrm{SO}_{4}$-catalyzed hydrolysis method 
Table 1 Chemical composition of transgenic rice cell walls

\begin{tabular}{|c|c|c|c|}
\hline & $\begin{array}{l}\text { Lignin, \% (fold change } \\
\text { vs untreated sample) }\end{array}$ & $\begin{array}{l}\text { Cellulose, } \% \text { (fold change } \\
\text { vs untreated sample) }\end{array}$ & $\begin{array}{l}\text { Hemicelluloses, } \% \text { (fold } \\
\text { change vs untreated } \\
\text { sample)c }\end{array}$ \\
\hline \multicolumn{4}{|l|}{ Untreated } \\
\hline WT & $15.4 \pm 1.4(-)$ & $41.3 \pm 0.7(-)$ & $42.4 \pm 1.7(-)$ \\
\hline OsCAld5H1-KD & $22.1 \pm 1.1(-)$ & $40.2 \pm 0.7(-)$ & $37.0 \pm 4.5(-)$ \\
\hline OsCAld5H1-OX & $16.5 \pm 0.9(-)$ & $37.9 \pm 0.5(-)$ & $38.9 \pm 1.3(-)$ \\
\hline $\mathrm{OsC} 3^{\prime} \mathrm{H} 1-\mathrm{KD}$ & $18.7 \pm 1.7(-)$ & $44.0 \pm 1.7(-)$ & $31.7 \pm 0.6(-)$ \\
\hline \multicolumn{4}{|c|}{ Dilute alkali (31.25 mM NaOH, $\left.90^{\circ} \mathrm{C}, 3 \mathrm{~h}\right)$} \\
\hline WT & $14.8 \pm 0.3(0.96)$ & $46.6 \pm 1.8(1.13)$ & $33.1 \pm 1.7(0.78)$ \\
\hline OsCAld5H1-KD & $17.4 \pm 1.7(0.79)$ & $47.4 \pm 0.2(1.18)$ & $33.4 \pm 1.6(0.90)$ \\
\hline OsCAld5H1-OX & $12.0 \pm 0.8(0.73)$ & $46.6 \pm 0.5(1.23)$ & $35.0 \pm 6.6(0.90)$ \\
\hline $\mathrm{OsC3} 3^{\prime} \mathrm{H} 1-\mathrm{KD}$ & $14.5 \pm 2.7(0.78)$ & $48.8 \pm 1.7(1.11)$ & $25.3 \pm 0.7(0.80)$ \\
\hline \multicolumn{4}{|c|}{ Dilute acid $\left(1.3 \% \mathrm{H}_{2} \mathrm{SO}_{4}, 90^{\circ} \mathrm{C}, 3 \mathrm{~h}\right)$} \\
\hline WT & $49.0 \pm 0.6(3.17)$ & $54.9 \pm 1.0(1.33)$ & $12.7 \pm 0.1(0.30)$ \\
\hline OsCAld5H1-KD & $51.1 \pm 1.3(2.31)$ & $56.1 \pm 1.2(1.40)$ & $9.9 \pm 1.1(0.27)$ \\
\hline OsCAld5H1-OX & $44.1 \pm 0.9(2.68)$ & $55.3 \pm 1.2(1.46)$ & $9.6 \pm 0.6(0.25)$ \\
\hline OsC3'H1-KD & $27.9 \pm 0.5(1.50)$ & $53.8 \pm 1.9(1.22)$ & $9.8 \pm 0.1(0.31)$ \\
\hline \multicolumn{4}{|c|}{ Liquid hot water $\left(200^{\circ} \mathrm{C}, 10 \mathrm{~min}\right)$} \\
\hline WT & $51.6 \pm 3.9(3.34)$ & $61.9 \pm 2.1(1.50)$ & $4.8 \pm 0.4(0.11)$ \\
\hline OsCAld5H1-KD & $56.7 \pm 0.9(2.56)$ & $61.4 \pm 4.0(1.53)$ & $3.9 \pm 0.2(0.11)$ \\
\hline OsCAld5H1-OX & $59.4 \pm 3.9(3.61)$ & $64.1 \pm 3.8(1.69)$ & $4.1 \pm 0.2(0.11)$ \\
\hline $\mathrm{OsC3} 3^{\prime} \mathrm{H} 1-\mathrm{KD}$ & $60.4 \pm 4.4(3.24)$ & $65.9 \pm 1.2(1.50)$ & $4.8 \pm 0.4(0.15)$ \\
\hline
\end{tabular}

$[39,40]$ estimated that the cellulose and hemicellulose contents varied from 38 to $44 \%$ and from 32 to $42 \%$ among the tested genotypes, respectively; OsC3 ${ }^{\prime} \mathrm{H} 1-\mathrm{KD}$ plants showed relatively higher cellulose (44\%) and lower hemicellulose $(32 \%)$ contents than the other genotypes (Table 1).

Next, the lignin structures were evaluated by 2D HSQC NMR and thioacidolysis. As expected, both analytical methods determined that OsCAld5H1-KD, OsCAld5H1-OX and OsC3'H1-KD transgenic culm lignins had significantly augmented G-, S- and H-type aromatic units, respectively, compared with the wild-type controls (Figs. 1a, b, 2 and Additional file 1: Table S1). HSQC NMR estimated 54\% G units in OsCAld5H1KD, 92\% S units in OsCAld5H1-OX and 75\% $\mathrm{H}$ units in $\mathrm{OsC3}$ 'H1-KD lignins compared with $48 \% \mathrm{G}, 48 \% \mathrm{~S}$ and $4 \% \mathrm{H}$ in wild-type lignins, based on the volume integration of the well-resolved $\mathrm{C}_{2 / 6}-\mathrm{H}_{2 / 6}$ signal contours [35] (Fig. 1b), whereas thioacidolysis determined $55 \% \mathrm{G}$ units in OsCAld5H1-KD, 83\% S units in OsCAld5H1-OX and $33 \% \mathrm{H}$ units in $\mathrm{OsC3}^{\prime} \mathrm{H} 1$-KD lignins compared with $47 \%$ G, $49 \% \mathrm{~S}$ and $4 \% \mathrm{H}$ in wild-type lignins (Fig. 2 and Additional file 1: Table S1); the differences between the G/S/H compositions estimated by HSQC NMR and thioacidolysis could be at least partially attributed to the fact that the latter measures only the distribution of monomers released by cleaving $\beta-O-4$ bonds [41]. The aromatic sub-regions of the HSQC NMR spectra also resolved sets of the signals from $p$-coumarate $(p C A)$ and tricin residues incorporated into the rice lignin polymers (Fig. 1a) [27-29]. Integral ratios of $p C A$ contour signals relative to the total of G/S/H aromatic signals were $102 \%, 125 \%, 86 \%$ and $216 \%$, whereas those of tricin contour signals were $18 \%, 22 \%, 13 \%$ and $52 \%$, in the wild-type, OsCAld5H1$\mathrm{KD}$, OsCAld5H1-OX and OsC3'H1-KD lignin spectra, respectively (Fig. 1c), suggesting that both $p C A$ and tricin residues were relatively augmented in the OsCAld5H1$\mathrm{KD}$ and $O s C 3^{\prime} H 1-\mathrm{KD}$ lignins and conversely depleted in the OsCAld5H1-OX lignins compared to in the wildtype lignins; it is notable that both $p C A$ and tricin signals could be over-represented in our HSQC NMR spectra because correlation signals from such mobile appendant or end group units in lignin polymers typically relax more slowly than those from less mobile internal units $[31,35]$. The aliphatic sub-regions of the HSQC NMR spectra further provided useful information on the distribution of 

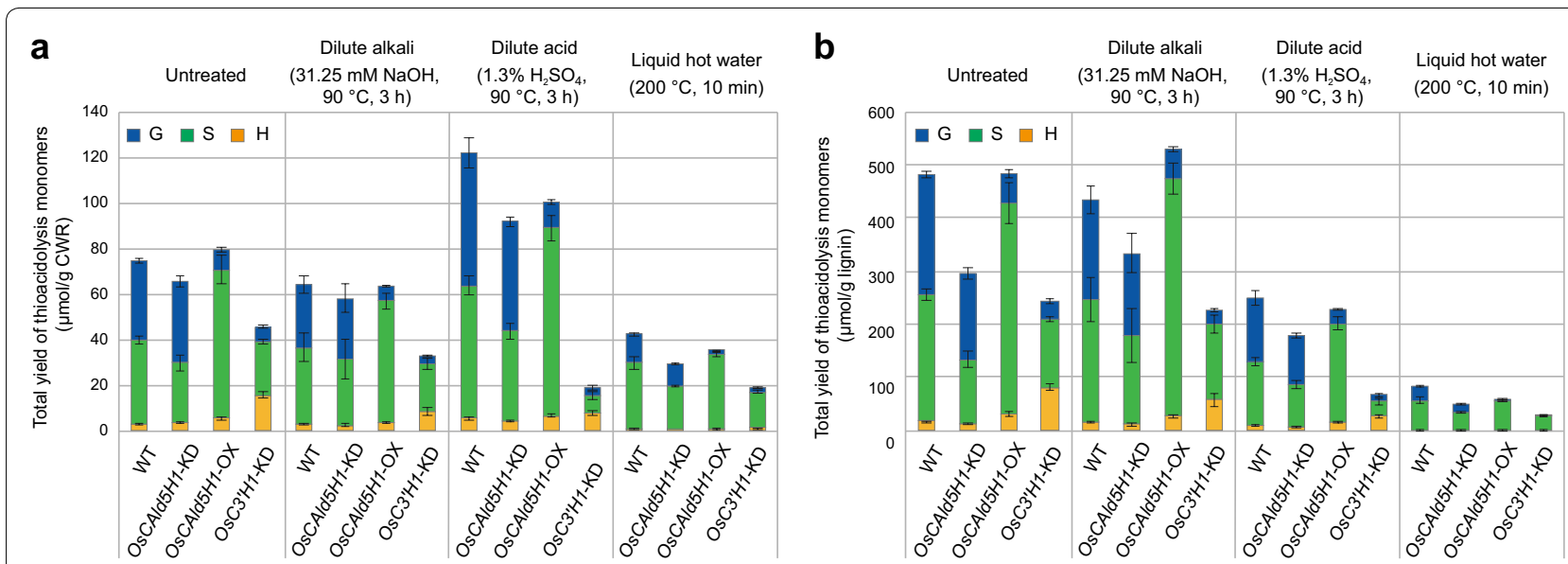

Fig. 2 Thioacidolysis-derived lignin composition of transgenic rice cell walls. Total yield of thioacidolysis monomers per cell wall residues (CWRs) (a) and per total lignin (b) are shown. Values are mean $\pm \mathrm{SD}(n=3)$. WT, wild-type; OsCAld5H1-KD, OsCAld5H1-knockdown; OsCAld5H1-OX, OsCAld5H1-overexpression; OsC3'H1-KD, OsC3'H1-knockdown

lignin inter-monomeric linkage types between the transgenic and wild-type lignin polymers (Fig. 1d). Quantitative analysis of the HSQC contour signals suggested that all the transgenic and wild-type lignins had similar lignin linkage distributions, being comprised mainly of $\beta-O-4$ linkages (I and $\mathrm{I}^{\prime} ;>80 \%$ of the total detectable linkage types) with lesser amounts of $\beta-5$ (II and II') and $\beta-\beta$ (III

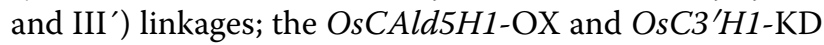
lines showed slightly increased $\beta-O-4$ and decreased $\beta-5$ units compared with the wild-type control and OsCAld5H1-KD line (Fig. 1e), which overall was consistent with our previously published data [27, 29].

\section{Chemical treatments of transgenic rice cell walls}

To investigate the effects of the altered lignin composition on the reactivity of rice lignocellulose in typical biomass processing reactions, the lignin-modified transgenic rice cell walls were subjected to dilute alkali, dilute acid and liquid hot water treatments; these thermochemical treatments have been frequently used as pretreatments to improve the enzymatic saccharification efficiency of lignocellulosic biomass [42-46]. The mass recovery rate (see "Methods/experimental") and lignocellulose structural changes were determined and compared between the lignin-altered transgenic and wild-type rice cell walls.

In the dilute alkali treatment (in $31.25 \mathrm{mM} \mathrm{NaOH}$ at $90{ }^{\circ} \mathrm{C}$ for $3 \mathrm{~h}$ ), the mass recovery rates were similar overall (76-81\%) among all the genotypes examined (Fig. 3). Lignocellulose compositional analyses by the Klason lignin and neutral sugar assays indicated that lignin and hemicellulose contents were decreased, while cellulose contents were increased after the alkaline treatment (Table 1). The data suggested that the alkali treatment preferentially extracted and removed lignins and hemicelluloses from the rice cell walls [46]. Interestingly, the decrease of lignin content was more prominent in the three transgenic lines $(0.73-0.79$-fold changes vs untreated samples) compared with the wild-type control (0.96-fold change vs untreated samples), although we found no significant differences in the degree of lignin removal among the three transgenic lines (Table 1). This result suggested that, regardless of the differences in aromatic composition, the transgenic rice lignins were somehow more susceptible to the alkaline treatment than the wild-type lignins. No drastic changes in the total yield or $\mathrm{H} / \mathrm{G} / \mathrm{S}$ composition of thioacidolysis-derived lignin monomers were detected after the alkaline treatment (Fig. 2 and Additional file 1: Table S1). Therefore, the current alkaline treatment had a minor effect on rice lignin structures, although previous studies have shown that more severe alkaline treatments may cleave the lignin polymer linkages and typically S-lignins are more easily degraded than G- or H-lignins under harsh alkali conditions [47-49].

By contrast, both the dilute acid (in $1.3 \% \mathrm{H}_{2} \mathrm{SO}_{4}$ at $90{ }^{\circ} \mathrm{C}$ for $3 \mathrm{~h}$ ) and liquid hot water (in compressed water at $200{ }^{\circ} \mathrm{C}$ for $10 \mathrm{~min}$ ) treatments largely reduced the hemicellulosic glycans, probably via acid-catalyzed hydrolysis, and eventually enriched lignins and cellulosic glucans (Table 1); in the typical liquid hot water process, cell wall-derived organic acids such as $p$-hydroxycinnamates, acetates, formates and glucuronic acids liberated in compressed hot water provoke acid-induced cell wall hydrolysis and condensation reactions [46]. It is, however, notable that lignin content of the acid and liquid hot water-treated cell walls evaluated by the Klason assay may be somehow 


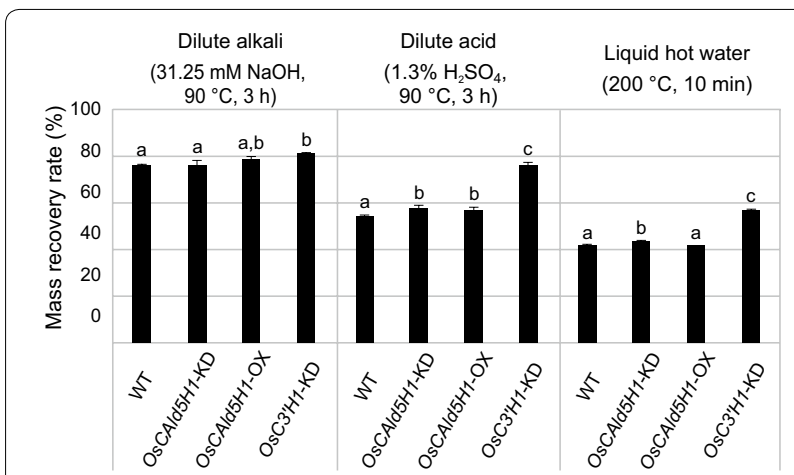

Fig. 3 Mass recovery rate after chemical treatments of transgenic rice cell walls. Values are mean $\pm \operatorname{SD}(n=3)$. Different letters indicate a significant difference between treatment conditions (ANOVA with post hoc Tukey-Kramer method, $p<0.05$ ). WT, wild-type; OsCAld5H1-KD, OsCAld5H1-knockdown; OsCAld5H1-OX, OsCAld5H1-overexpression; OsC3 'H1-KD, OsC3 'H1-knockdown

overestimated by repolymerized polysaccharide degradation products (pseudo-lignins) (Table 1) [44, 50]. The mass recovery rate (Fig. 3) and the hemicellulose content data (Table 1) suggested that the liquid hot water treatment was likely harsher and more effective in hemicellulose removal than the dilute acid treatment employed in this study. Notably, the $O s C 3^{\prime} H 1-\mathrm{KD}$ line showed significantly higher mass recovery rates than the other genotypes in both the dilute acid and liquid hot water treatments (Fig. 3), which might have been due to the relatively low hemicellulose levels in the original cell walls from the $O s C 3^{\prime} H 1-\mathrm{KD}$ line compared with those from the other genotypes (Table 1). Despite the large increases in lignin content (Table 1), the total yields of thioacidolysis monomers expressed per total lignin content were largely depleted after the acid and liquid hot water treatments for all the tested rice cell walls (Fig. $2 \mathrm{~b}$ and Additional file 1: Table S1), suggesting that lignins underwent acid-induced condensation reactions in both the dilute acid and liquid hot water treatments. We again observed more pronounced monomer yield reductions after liquid hot water treatment than after dilute acid treatment (Fig. $2 \mathrm{~b}$ and Additional file 1: Table S1). Particularly after the liquid hot water treatment, both H- and G-type thioacidolysis monomers were more drastically depleted than S-type monomers (Fig. 2b and Additional file 1: Table S1). The result suggests that $\mathrm{H}$ - and G-lignins are more susceptible to acid-induced condensation reactions than S-lignins, possibly due to the higher reactivities of non- or less methoxylated $\mathrm{H}$ - and G-type aromatic rings than
S-type aromatic rings in typical acid-catalyzed condensation reactions of lignins [51-53].

\section{Enzymatic saccharification efficiency of transgenic rice cell walls}

To assess the effects of altered lignin composition on cell wall degradability, we evaluated the enzymatic saccharification efficiency of the rice cell wall samples with and without chemical pretreatments. In line with our previous data [29], raw untreated cell walls from the $\mathrm{H}$-lignin-augmented $\mathrm{OsC} 3^{\prime} \mathrm{H} 1-\mathrm{KD}$ line displayed a significantly higher saccharification efficiency (51\% per total glucan) than the wild-type control cell walls ( $42 \%$ per total glucan) (Fig. 4). A similar improvement in cell wall saccharification efficiency was also reported for $\mathrm{H}$-ligninenriched Arabidopsis mutants [54]. Thus, H-lignin may show a lower inhibitory effect than G-and S-lignins on cell wall hydrolysis by cellulolytic enzymes $[54,55]$. In addition, we previously determined that cell wall crosslinking ferulates specific to grass cell walls were substantially reduced in $\mathrm{OsC} 3^{\prime} \mathrm{H} 1-\mathrm{KD}$ rice cell walls, which may also contribute to the enhancement of cell wall digestibility [29]. In contrast, G-lignin-augmented OsCAld5H1KD (39\% per total glucan) and S-lignin-augmented OsCAld5H1-OX (41\% per total glucan) cell walls showed similar saccharification efficiencies to the wild-type control (42\% per total glucan) (Fig. 4), suggesting that the S/G ratio does not much affect the biomass saccharification efficiency without any pretreatment. Similarly, analogous studies with transgenic alfalfa [18], Arabidopsis $[19,21-23]$ and poplar [20] also noted that changes in S/G ratio had a minor impact on the digestibility of eudicot cell walls without thermochemical pretreatment.

Next, we investigated the enzymatic saccharification in combination with the dilute alkali, dilute acid and liquid hot water treatments. All the pretreatments greatly enhanced the glucose yields, by $40-213 \mathrm{mg} / \mathrm{g}$ cell walls or $9-50 \%$ per total glucan after $24 \mathrm{~h}$ of enzymatic hydrolysis (Fig. 4). Like we observed with untreated cell wall samples, the $\mathrm{H}$-lignin-augmented $\mathrm{OsC} 3^{\prime} \mathrm{H} 1-\mathrm{KD}$ line showed significantly higher glucose yields than the wild-type control, whereas the OsCAld5H1-KD and OsCAld5H1-OX lines displayed overall similar glucose yields to the wild-type control with dilute alkali and acid pretreatments (Fig. 4). However, the S-lignin-enriched OsCAld5H1-OX line displayed a dramatically increased glucose yield (91\% per total glucan) compared to other genotypes $(60-73 \%$ per total glucan) after liquid hot water pretreatment (Fig. 4). A similar result was reported in earlier studies with transgenic Arabidopsis and natural poplar variants; increasing the proportions of S units in lignins likewise improved the enzymatic hydrolysis of cellulose when combined with hot water pretreatments 

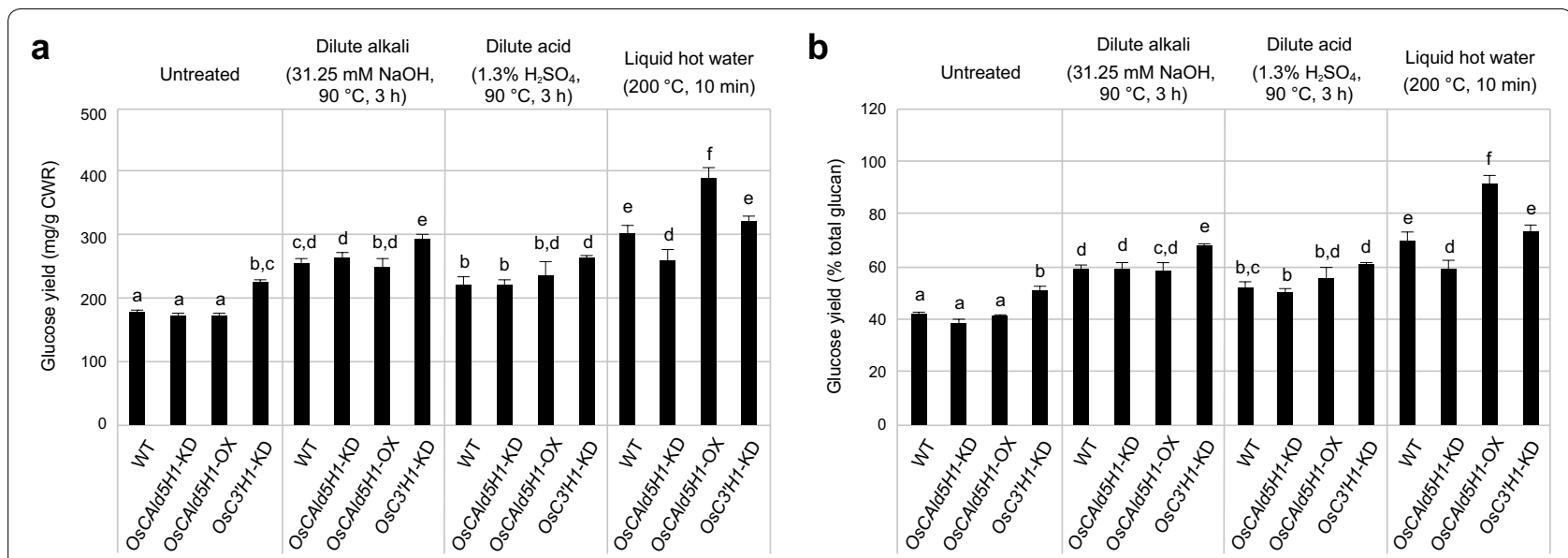

Fig. 4 The enzymatic saccharification efficiency of transgenic rice cell walls. Glucose yields from cell walls after $24 \mathrm{~h}$ enzymatic hydrolysis are shown. The efficiency is expressed as glucose yield per cell wall residue (CWR) (a) and as glucose yield per total glucan (b). Values are mean \pm SD $(n=3)$. Different letters indicate a significant difference (ANOVA with post hoc Tukey-Kramer method, $p<0.05)$. WT, wild-type; OsCAld5H1-KD, OsCAld5H1-knockdown; OsCAld5H1-OX, OsCAld5H1-overexpression; OsC3'H1-KD, OsC3 'H1-knockdown

$[19,56]$. The actual reason why liquid hot water processing enhances the enzymatic saccharification of S-ligninenriched plants remain unknown; Li et al. speculated that S-rich lignins might have lower melting points than G-rich lignins and thus might be more easily melted and relocated under high-temperature conditions [19]. In contrast, with the liquid hot water pretreatment, the G-lignin-enriched OsCAld5H1-KD line (60\% per total glucan), and even the $\mathrm{H}$-lignin-enriched $\mathrm{OsC} 3^{\prime} \mathrm{H} 1-\mathrm{KD}$ line (73\% per total glucan), which displayed improved saccharification efficiency with no pretreatment conditions, displayed similar or lower glucose yields compared with the wild-type control (70\% per total glucan). Taken together with the structural analysis data discussed earlier (Table 1, Fig. 2 and Additional file 1: Table S1), the highly condensed lignins derived via liquid hot water treatment of G- and H-lignins may be more recalcitrant than the lignins derived via the treatment of S-lignins, by impeding the accessibility and/or the catalytic activity of hydrolytic enzymes. Overall, our data demonstrate that modulations of the H-/G-/S-lignin composition can be a promising strategy to enhance enzymatic saccharification of grass biomass to boost the production of fermentable sugars.

\section{Calorific values of transgenic rice cell walls}

The calorific value is an important trait that directly correlates to the performance of biomass in solid fuel applications, so we lastly evaluated the HHVs of the rice transgenic cell walls. For comparison, we determined the HHVs of CWRs, lignin-enriched CWRs prepared via cellulolytic hydrolysis of CWRs (Additional file 1: Table S2) and synthetic lignins (dehydrogenation polymers, DHPs) comprising only G (G-DHP), S (S-DHP) or H (H-DHP) aromatic units $[32,33]$. For all rice cell wall and DHP samples, the HHVs were estimated based on the elemental composition using the equation proposed by Yin [37]. In parallel, the actual HHVs of rice cell wall samples were measured by bomb calorimetry.

In line with the notion that HHV of biomass is positively correlated with the lignin content $[3,16,17,57-$ 59], the HHVs of lignin-enriched CWRs were generally higher than those of untreated CWRs, as determined by both elemental analysis and bomb calorimetry (Table 2). Because the degree of lignin methoxylation negatively correlates with the carbon contents of lignin polymers, an increase of less methoxylated H- or G-lignins over S-lignins may increase lignin HHVs [3]. In fact, the calculated HHVs determined for the DHPs were the highest for H-DHP $(23,720 \mathrm{~J} / \mathrm{g})$, followed by G-DHP $(21,880 \mathrm{~J} / \mathrm{g})$ and S-DHP $(21,280 \mathrm{~J} / \mathrm{g})$ (Table 2). We also found that the calculated HHVs of lignin-enriched CWRs determined for the G-lignin-augmented OsCAld5H1-KD (20,710 J/g) and the $\mathrm{H}$-lignin-augmented $\mathrm{OsC} 3^{\prime} \mathrm{H} 1-\mathrm{KD}(20,710 \mathrm{~J} / \mathrm{g})$ lines were statistically higher than those determined for the S-lignin-augmented OsCAld5H1-OX line (20,220 J/g) and the wild-type control $(20,360 \mathrm{~J} / \mathrm{g})$; we did not detect such a tendency in the untreated CWR samples, possibly because of their low lignin levels (Table 2). These data are in line with the notion that enrichment of less methoxylated H- or G-lignins could be beneficial to improving the heating value of lignin-based solid biofuels. Consequently, however, we did not detect any statistically significant differences in the actual HHVs determined by bomb calorimetry between the rice cell walls from the three transgenic lines and the wild-type control, either 
Table 2 Elemental composition and higher heating values (HHVs) of transgenic rice cell walls and synthetic lignins

\begin{tabular}{|c|c|c|c|c|c|c|}
\hline & \multicolumn{4}{|c|}{ Elemental composition (\%) } & \multicolumn{2}{|l|}{$\operatorname{HHV}^{b}(J / g)$} \\
\hline & $\mathrm{C}$ & $\mathbf{H}$ & 0 & $\mathrm{~N}$ & $\begin{array}{l}\text { By elemental } \\
\text { composition }\end{array}$ & By bomb calorimetry \\
\hline \multicolumn{7}{|c|}{ Cell wall residue (CWR) } \\
\hline WT & $44.8 \pm 0.1$ & $5.9 \pm 0.0$ & $48.9 \pm 0.1$ & $0.4 \pm 0.1$ & $18,100 \pm 30^{B}$ & $18,760 \pm 400^{A}$ \\
\hline OsCAld5H1-KD & $44.2 \pm 0.1$ & $6.0 \pm 0.0$ & $49.4 \pm 0.2$ & $0.4 \pm 0.1$ & $17,970 \pm 40^{A, B}$ & $18,820 \pm 790^{A}$ \\
\hline OsCAld5H1-OX & $44.8 \pm 0.1$ & $6.0 \pm 0.0$ & $48.2 \pm 0.2$ & $0.9 \pm 0.0$ & $18,190 \pm 40^{B}$ & $19,560 \pm 910^{A, B}$ \\
\hline OsC3'H1-KD & $43.8 \pm 0.1$ & $5.9 \pm 0.0$ & $49.4 \pm 0.1$ & $0.9 \pm 0.0$ & $17,820 \pm 80^{\mathrm{A}}$ & $18,330 \pm 370^{\mathrm{A}}$ \\
\hline \multicolumn{7}{|c|}{ Lignin-enriched CWR ${ }^{\mathrm{a}}$} \\
\hline WT & $52.9 \pm 0.1$ & $5.8 \pm 0.1$ & $40.3 \pm 0.1$ & $1.0 \pm 0.0$ & $20,360 \pm 70^{C}$ & $22,080 \pm 1430^{B, C}$ \\
\hline OsCAld5H1-KD & $54.1 \pm 0.0$ & $5.8 \pm 0.0$ & $39.0 \pm 0.1$ & $1.1 \pm 0.0$ & $20,710 \pm 50^{\mathrm{D}}$ & $22,650 \pm 340^{c}$ \\
\hline OsCAld5H1-OX & $52.3 \pm 0.1$ & $5.8 \pm 0.1$ & $40.2 \pm 0.2$ & $1.7 \pm 0.0$ & $20,220 \pm 90^{c}$ & $21,640 \pm 1410^{B, C}$ \\
\hline $\mathrm{OsC3}^{\prime} \mathrm{H} 1-\mathrm{KD}$ & $53.7 \pm 0.4$ & $5.9 \pm 0.2$ & $38.1 \pm 0.6$ & $2.4 \pm 0.2$ & $20,710 \pm 190^{D}$ & $20,920 \pm 1950^{A, C}$ \\
\hline \multicolumn{7}{|l|}{ Synthetic lignin } \\
\hline G-DHP & $59.1 \pm 0.2$ & $5.4 \pm 0.1$ & $35.3 \pm 0.2$ & $0.2 \pm 0.0$ & $21,880 \pm 70^{F}$ & ND \\
\hline S-DHP & $56.0 \pm 0.1$ & $5.8 \pm 0.0$ & $36.5 \pm 0.0$ & $1.7 \pm 0.1$ & $21,280 \pm 40^{\mathrm{E}}$ & ND \\
\hline $\mathrm{H}-\mathrm{DHP}$ & $65.3 \pm 0.1$ & $5.4 \pm 0.1$ & $28.7 \pm 0.2$ & $0.6 \pm 0.0$ & $23,720 \pm 110^{G}$ & ND \\
\hline
\end{tabular}

ND, not determined; WT, wild-type; OsCAld5H1-KD, OsCAld5H1-knockdown; OsCAld5H1-OX, OsCAld5H1-overexpression; OsC3 ' H1-KD, OsC3 'H1-knockdown

a Cell wall residues after enzymatic hydrolysis of the polysaccharide fraction with crude cellulases. Isolation yields and cell wall sugar composition are shown in Additional file 1: Table S2

b Different letters indicate a significant difference between datasets (ANOVA with post hoc Tukey-Kramer method, $p<0.05$ ). Elemental composition and HHV results are reported on an ash-free basis. Values are mean $\pm \mathrm{SD}(n=3)$

among the untreated CWR or among the lignin-enriched CWR samples (Table 2). This might have been because of the variations in the inter-mixed polysaccharides and/or lignin components other than the $\mathrm{G} / \mathrm{S} / \mathrm{H}$ aromatic units (Table 1 and Additional file 1: Table S2). For example, the elevations of lignin HHVs by the augmentation of $\mathrm{G}$ and $\mathrm{H}$ units in the OsCAld5H1-KD and OsC3'H1-KD lignins could be somehow offset by the increase in the relatively oxygen-rich $p C A$ and tricin residues as suggested by our NMR analysis (Fig. 1c).

\section{Conclusions}

To gain insight into the effects of lignin composition on biomass properties in grasses, we comparatively evaluate the biomass reactivity, enzymatic saccharification with or without pretreatments and calorific values of our recently produced rice transgenic lines with distinct lignin monomer compositions. Our data demonstrated that the enrichment of $\mathrm{H}$-lignins can be effective in enhancing biomass saccharification efficiency with alkali and acid pretreatments or even without any pretreatment. Additionally, the enrichment of S-lignins greatly enhanced cell wall saccharification with liquid hot water pretreatment. While the total lignin content showed a clear positive effect on the heating value of rice cell walls, modulating lignin aromatic composition had no effect on the heating values at least for the rice cell wall materials used in this study. However, because the analysis of synthetic lignin models demonstrated a negative correlation between the methoxyl content and lignin heating value, further genetic enrichment of less methoxylated H- or G-lignins, in combination with an increase of total lignin content, may help to increase the biomass heating value. We believe that further cell wall analysis of ligninmodified transgenic rice plants will greatly help us identify a potent strategy for developing biorefinery-suited grass biomass feedstocks.

\section{Additional file}

Additional file 1: Table S1. Thioacidolysis-derived lignin composition of transgenic rice cell walls. Table S2. Isolation yields and cell wall sugar composition of lignin-enriched cell walls from transgenic rice.

\section{Abbreviations}

CWR: cell wall residue; DHP: dehydrogenation polymer; DMSO: dimethylsulfoxide; G: guaiacyl; H: p-hydroxyphenyl; HHV: higher heating value; HSQC: heteronuclear single-quantum coherence; KD: knockdown; NMR: nuclear magnetic resonance; OX: overexpression; S: syringyl; TFA: trifluoroacetic acid.

\section{Authors' contributions}

YurT, YukT, MS and TU designed the research. YurT, YukT, MY and TT performed the experiments. YurT, YukT and TU analyzed the data and wrote the manuscript with contributions of all the other authors. All authors read and approved the final manuscript.

\section{Author details}

${ }^{1}$ Research Institute for Sustainable Humanosphere, Kyoto University, Uji, Kyoto 611-0011, Japan. ${ }^{2}$ Graduate School of Agriculture, Kyoto University, Sakyo-ku, 
Kyoto 606-8502, Japan. ${ }^{3}$ Research Unit for Development of Global Sustainability, Kyoto University, Uji, Kyoto 611-0011, Japan.

\section{Acknowledgements}

We thank Dr. Hironori Kaji and Ayaka Maeno (ICR, Kyoto University) for their assistance in NMR analysis, and Dr. Kazuaki Katagiri, Shimpei Yamaguchi and Takuya Ehiro (Osaka Research Institute of Industrial Science and Technology) for bomb calorimetry.

\section{Competing interests}

The authors declare that they have no competing interests.

\section{Availability of data and materials}

All data generated or analyzed during this study are included in this published article and its additional files.

\section{Funding}

This work was supported in part by grants from the Japan Science and Technology Agency/Japan International Cooperation Agency (Science and Technology Research Partnership for Sustainable Development, SATREPS), the Japan Society for the Promotion of Science (KAKENHI, \#16H06198 and \#16K14958), and RISH, Kyoto University (Mission-linked Research Funding, \#2016-5-2-1). YurT acknowledges the JSPS fellowship program (\#17J09654). Part of this study was conducted using the facilities in the DASH/FBAS at RISH, Kyoto University, and the NMR spectrometer in the JURC at ICR, Kyoto University.

\section{Publisher's Note}

Springer Nature remains neutral with regard to jurisdictional claims in published maps and institutional affiliations.

Received: 20 September 2018 Accepted: 4 December 2018

Published online: 13 February 2019

\section{References}

1. Griggs D, Stafford-Smith M, Graffney O, Rockström J, Öhman MC, Shyamsunder P, Steffen W, Glaser G, Kanie N, Noble I (2013) Policy: sustainable development goals for people and planet. Nature 495:305-307

2. Tye YY, Lee KT, Wan Abdullah WN, Leh CP (2016) The world availability of non-wood lignocellulosic biomass for the production of cellulosic ethanol and potential pretreatments for the enhancement of enzymatic saccharification. Renew Sustain Ener Rev 60:155-172

3. Umezawa T (2018) Lignin modification for valorization. Phytochem Rev 17:1305-1327

4. Bhatia R, Gallagher JA, Gomez LD, Bosch M (2017) Genetic engineering of grass cell wall polysaccharides for biorefining. Plant Biotechnol J 15:1071-1092

5. de Moraes Rocha GJ, Martin C, Soares IB, Maior AMS, Baudel HM, de Abreu CAM (2011) Dilute mixed-acid pretreatment of sugarcane bagasse for ethanol production. Biomass Bioenerg 35:663-670

6. Bezerra TL, Ragauskas AJ (2016) A review of sugarcane bagasse for second-generation bioethanol and biopower production. Biofuels Bioprod Bioref 10:634-647

7. Boerjan W, Ralph J, Baucher M (2003) Lignin biosynthesis. Annu Rev Plant Biol 54:519-546

8. Ralph J (2010) Hydroxycinnamates in lignification. Phytochem Rev 9:65-83

9. Lan W, Lu F, Regner M, Zhu Y, Rencoret J, Ralph SA, Zakai UI, Morreel K, Boerjan W, Ralph J (2015) Tricin, a flavonoid monomer in monocot lignification. Plant Physiol 167:1284-1295

10. Chiang VL (2006) Monolignol biosynthesis and genetic engineering of lignin in trees, a review. Environ Chem Lett 4:143-146

11. Vanholme R, Morreel K, Ralph J, Boerjan W (2008) Lignin engineering. Curr Opin Plant Biol 11:278-285

12. Wang P, Dudareva N, Morgan JA, Chapple C (2015) Genetic manipulation of lignocellulosic biomass for bioenergy. Curr Opin Chem Biol 29:32-39
13. Mottiar Y, Vanholme R, Boerjan W, Ralph J, Mansfield SD (2016) Designer lignins: harnessing the plasticity of lignification. Curr Opin Biotechnol 37:190-200

14. Ragauskas AJ, Beckham GT, Biddy MJ, Chandra R, Chen F, Davis MF, Davison BH, Dixon RA, Gilna P, Keller M, Langan P, Naskar AK, Saddler JN, Tschaplinski TJ, Tuskan GA, Wyman CE (2014) Lignin valorization: improving lignin processing in the biorefinery. Science 344:1246843

15. Rinaldi R, Jastrzebski R, Clough MT, Ralph J, Kennema M, Bruijnincx PC, Weckhuysen BM (2016) Paving the way for lignin valorization: recent advances in bioengineering, biorefining and catalysis. Angew Chem Int Ed Engl 55:8164-8215

16. Scully ED, Gries T, Sarath G, Palmer NA, Baird L, Serapiglia MJ, Dien BS, Boateng AA, Ge Z, Funnell-Harris DL, Twigg P, Clemente TE, Sattler SE (2016) Overexpression of SbMyb60 impacts phenylpropanoid biosynthesis and alters secondary cell wall composition in Sorghum bicolor. Plant J 85:378-395

17. Koshiba T, Yamamoto N, Tobimatsu Y, Yamamura M, Suzuki S, Hattori T, Mukai M, Noda S, Shibata D, Sakamoto M, Umezawa T (2017) MYB-mediated upregulation of lignin biosynthesis in Oryza sativa towards biomass refinery. Plant Biotechnol 34:7-15

18. Chen F, Dixon RA (2007) Lignin modification improves fermentable sugar yields for biofuel production. Nat Biotechnol 25:759-761

19. Li X, Ximenes E, Kim Y, Slininger M, Meilan R, Ladisch M, Chapple C (2010) Lignin monomer composition affects Arabidopsis cell-wall degradability after liquid hot water pretreatment. Biotechnol Biofuels 3:27-33

20. Mansfield SD, Kang K-Y, Chapple C (2012) Designed for deconstruction-poplar trees altered in cell wall lignification improve the efficacy of bioethanol production. New Phytol 194:91-101

21. Van Acker R, Vanholme R, Storme V, Mortimer JC, Dupree P, Boerjan W (2013) Lignin biosynthesis perturbations affect secondary cell wall composition and saccharification yield in Arabidopsis thaliana. Biotechnol Biofuels 6:46-62

22. Anderson NA, Tobimatsu Y, Ciesielski PN, Ximenes E, Ralph J, Donohoe BS, Ladisch M, Chapple C (2015) Manipulation of guaiacyl and syringyl monomer biosynthesis in an arabidopsis cinnamyl alcohol dehydrogenase mutant results in atypical lignin biosynthesis and modified cell wall structure. Plant Cell 27:2195-2209

23. Shi J, Pattathil S, Parthasarathi R, Anderson NA, Kim Jl, Venketachalam S, Hahn MG, Chapple C, Simmons BA, Singh S (2016) Impact of engineered lignin composition on biomass recalcitrance and ionic liquid pretreatment efficiency. Green Chem 18:4884-4895

24. Fu C, Mielenz JR, Xiao X, Ge Y, Hamilton CY, Rodriguez M Jr, Chen F, Foston M, Ragauskas A, Bouton J, Dixon RA, Wang ZY (2011) Genetic manipulation of lignin reduces recalcitrance and improves ethanol production from switchgrass. Proc Natl Acad Sci USA 108:3803-3808

25. Cesarino I, Simões MS, dos Santos Brito M, Fanelli A, da Franca Silva T, Romanel E (2016) Building the wall: recent advances in understanding lignin metabolism in grasses. Acta Physiol Plant 38:269

26. Hatfield RD, Rancour DM, Marita JM (2017) Grass cell walls: A story of cross-linking. Front Plant Sci 7:2056

27. Takeda Y, Koshiba T, Tobimatsu Y, Suzuki S, Murakami S, Yamamura M, Rahman MM, Takano T, Hattori T, Sakamoto M, Umezawa T (2017) Regulation of CONIFERALDEHYDE 5-HYDROXYLASE expression to modulate cell wall lignin structure in rice. Planta 246:337-349

28. Takeda Y, Suzuki S, Tobimatsu Y, Osakabe K, Osakabe Y, Ragamustari SK, Sakamoto M, Umezawa T (2018) Lignin characterization of rice CONIFERALDEHYDE 5-HYDROXYLASE loss-of-function mutants generated with the CRISPR/Cas9 system. Plant J. https://doi.org/10.1111/tpj.14141

29. Takeda Y, Tobimatsu Y, Karlen SD, Koshiba T, Suzuki S, Yamamura M, Murakami S, Mukai M, Hattori T, Osakabe K, Ralph J, Sakamoto M, Umezawa T (2018) Downregulation of p-COUMAROYL ESTER 3-HYDROXYLASE in rice leads to altered cell wall structures and improves biomass saccharification. Plant J 95:796-811

30. Yamamura M, Hattori T, Suzuki S, Shibata D, Umezawa T (2012) Microscale thioacidolysis method for the rapid analysis of $\beta-0-4$ substructures in lignin. Plant Biotechnol 29:419-423 
31. Tobimatsu Y, Chen F, Nakashima J, Escamilla-Trevino LL, Jackson L, Dixon RA, Ralph J (2013) Coexistence but independent biosynthesis of catechyl and guaiacyl/syringyl lignin polymers in seed coats. Plant Cell 25:2587-2600

32. Tobimatsu Y, Takano T, Kamitakahara H, Nakatsubo F (2008) Studies on the dehydrogenative polymerizations of monolignol $\beta$-glycosides. Part 3: horseradish peroxidase-catalyzed polymerizations of triandrin and isosyringin. J Wood Chem Technol 28:69-83

33. Sawamura K, Tobimatsu Y, Kamitakahara H, Takano T (2017) Lignin functionalization through chemical demethylation: preparation and tannin-like properties of demethylated guaiacyl-type synthetic lignins. ACS Sustain Chem Eng 5:5424-5431

34. Santoro N, Cantu SL, Tornqvist C-E, Falbel TG, Bolivar UL, Patterson SE, Pauly M, Walton JD (2010) A high-throughput platform for screening milligram quantities of plant biomass for lignocellulose digestibility. Bioenerg Res 3:93-102

35. Mansfield SD, Kim H, Lu F, Ralph J (2012) Whole plant cell wall characterization using solution-state 2D NMR. Nat Protoc 7:1579-1589

36. Hattori T, Murakami S, Mukai M, Yamada T, Hirochika H, Ike M, Tokuyasu K, Suzuki S, Sakamoto M, Umezawa T (2012) Rapid analysis of transgenic rice straw using near-infrared spectroscopy. Plant Biotechnol 29:359-366

37. Yin C-Y (2011) Prediction of higher heating values of biomass from proximate and ultimate analyses. Fuel 90:1128-1132

38. Hatfield RD, Jung H-JG, Ralph J, Buxton DR, Weimer PJ (1994) A comparison of the insoluble residues produced by the Klason lignin and acid detergent lignin procedures. J Sci Food Agric 65:51-58

39. Foster CE, Martin TM, Pauly M (2010) Comprehensive compositional analysis of plant cell walls (lignocellulosic biomass) part Il: carbohydrates. J Vis Exp 37:1837

40. Lam PY, Tobimatsu Y, Takeda Y, Suzuki S, Yamamura M, Umezawa T, Lo C (2017) Disrupting flavone synthase II alters lignin and improves biomass digestibility. Plant Physiol 174:972-985

41. Lapierre C, Monties B, Rolando C (1986) Preparative thioacidolysis of spruce lignin: isolation and identification of main monomeric products. Holzforschung 40:47-50

42. Yu Q, Zhuang X, Lv S, He M, Zhang Y, Yuan Z, Qi W, Wang Q, Wang W, Tan $X$ (2013) Liquid hot water pretreatment of sugarcane bagasse and its comparison with chemical pretreatment methods for the sugar recovery and structural changes. Bioresour Technol 129:592-598

43. Alvira P, Tomás-Pejó E, Ballesteros M, Negro MJ (2010) Pretreatment technologies for an efficient bioethanol production process based on enzymatic hydrolysis: a review. Bioresour Technol 101:4851-4861

44. Hu F, Ragauskas A (2012) Pretreatment and lignocellulosic chemistry. Bioenerg Res 5:1043-1066

45. Mood SH, Golfeshan AH, Tabatabaei M, Jouzani GS, Najafi GH, Gholami M, Ardjmand M (2013) Lignocellulosic biomass to bioethanol, a comprehensive review with a focus on pretreatment. Renew Sustain Ener Rev 27:77-93
46. Kim TH (2013) Pretreatment of lignocellulosic biomass. In: Yang S, ElEnshasy HA, Thongchul N (eds) Bioprocessing technologies in biorefinery for sustainable production of fuels, chemicals, and polymers. Wiley, New Jersey, pp 91-105

47. Huntley SK, Ellis D, Gilbert M, Chapple C, Mansfield SD (2003) Significant increases in pulping efficiency in $\mathrm{C} 4 \mathrm{H}$-F5H-transformed poplars: improved chemical savings and reduced environmental toxins. J Agric Food Chem 51:6178-6183

48. Shimizu S, Yokoyama T, Akiyama T, Matsumoto Y (2012) Reactivity of lignin with different composition of aromatic syringyl/guaiacyl structures and erythro/threo side chain structures in $\beta-O-4$ type during alkaline delignification: as a basis for the different degradability of hardwood and softwood lignin. J Agric Food Chem 60:6471-6476

49. Wagner A, Tobimatsu Y, Phillips L, Flint H, Geddes B, Lu F, Ralph J (2015) Syringyl lignin production in conifers: proof of concept in a pine tracheary element system. Proc Natl Acad Sci USA 112:6218-6223

50. Sannigrahi P, Kim DH, Jung S, Ragauskas A (2011) Pseudo-lignin and pretreatment chemistry. Energy Environ Sci 4:1306-1310

51. Miyamoto T, Mihashi A, Yamamura M, Tobimatsu Y, Suzuki S, Takada R, Kobayashi Y, Toshiaki U (2018) Comparative analysis of lignin chemical structures of sugarcane bagasse pretreated by alkaline, hydrothermal, and dilute sulfuric acid methods. Ind Crops Prod 121:124-131

52. Shioya T, Akiyama T, Yokoyama T, Matsumoto Y (2016) Formation rate of benzyl cation intermediate from $p$-hydroxyphenyl, guaiacyl, or syringyl nucleus in acidolysis of lignin. J Wood Chem Technol 37:75-86

53. Wayman M, Chua MGS (1979) Characterization of autohydrolysis aspen (P. tremuloides) lignins. Part 2. Alkaline nitrobenzene oxidation studies of extracted autohydrolysis lignin. Can J Chem 57:2599-2602

54. Bonawitz ND, Kim JI, Tobimatsu Y, Ciesielski PN, Anderson NA, Ximenes E, Maeda J, Ralph J, Donohoe BS, Ladisch M, Chapple C (2014) Disruption of mediator rescues the stunted growth of a lignin-deficient Arabidopsis mutant. Nature 509:376-380

55. Sangha AK, Davison BH, Standaert RF, Davis MF, Smith JC, Parks JM (2014) Chemical factors that control lignin polymerization. J Phys Chem B 118:164-170

56. Studer MH, DeMartini JD, Davis MF, Sykes RW, Davison B, Keller M, Tuskan GA, Wyman CE (2011) Lignin content in natural Populus variants affects sugar release. Proc Natl Acad Sci USA 108:6300-6305

57. Demirbaş A (2001) Relationships between lignin contents and heating values of biomass. Energy Convers Manag 42:183-188

58. Vargas-Moreno JM, Callejón-Ferre AJ, Pérez-Alonso J, Velázquez-Martí B (2012) A review of the mathematical models for predicting the heating value of biomass materials. Renew Sustain Ener Rev 16:3065-3083

59. Kačík F, Ďurkovič J, Kačíková D (2012) Chemical profiles of wood components of poplar clones for their energy utilization. Energies 5:5243-5256

\section{Submit your manuscript to a SpringerOpen ${ }^{\circ}$ journal and benefit from:}

- Convenient online submission

- Rigorous peer review

- Open access: articles freely available online

- High visibility within the field

Retaining the copyright to your article

Submit your next manuscript at $\gg$ springeropen.com 